\title{
TRANSLATION AND VALIDATION OF THE GENOS EMOTIONAL INTELLIGENCE INVENTORY (CONCISE VERSION) FOR USE IN SRI LANKA
}

\author{
D. Edussuriya ${ }^{1}$, S.U.B. Tennakoon ${ }^{2}$, K.N. Marambe ${ }^{3}$, R.M.I.S.D. Rathnayake ${ }^{1}$, B.G. Premaratne', \\ S.K. Ubhayasiri ${ }^{1}$ \\ ${ }^{1}$ Department of Forensic Medicine, University of Peradeniya, Sri Lanka \\ ${ }^{2}$ Department of Community Medicine, University of Peradeniya, Sri Lanka \\ ${ }^{3}$ Medical Education Unit, University of Peradeniya, Sri Lanka \\ Corresponding author: Dr. D.Edussuriya - deepthiforensic2000@gmail.com
}

\begin{abstract}
Background: Emotional Intelligence (EI) is a multi-dimensional concept.The Genos EI Inventory is designed to measure the frequency with which an individual displays emotionally intelligent behaviours across seven dimensions. There is paucity of research on EI of individuals in the healthcare sector and lack of an appropriate instrument for the assessment of EI in Sri Lanka.
\end{abstract}

Objectives: To translate the Genos EI inventory (concise version) to Sinhala language and to validate it to be used among Sri Lankan medical students

Method: Genos EI inventory was translated to Sinhala and administered to 50 medical students. The internal reliability scores were checked by calculating Chronbach's alpha using SPSS v22.0 and the values were compared with the reference values for the original questionnaire.

Results: Reliability of the translated questionnaire was 0.89 and the Chronbach's alpha for six out of seven subscales met the appropriate reliability scores.

Conclusions: Translated Sinhala version of the Genos EI inventory is found to be reliable to be used among Sri Lankan medical students.

Key words: Emotional Intelligence, Genos EI inventory, medical students

\section{Introduction}

The concept of Emotional Intelligence (EI) was introduced in the early 1990s by Salovey and Mayer ${ }^{1}$ who defined it as "a type of social intelligence that involves the ability to monitor one's own and others emotions, to discriminate among them, and to use this information to guide one's thinking and actions." Emotional Intelligence is multidimensional concept. It has been proven that people with good EI show better social functioning and interpersonal relationship and that peers have identified them as less antagonistic and conflictual ${ }^{2}$.

The literature reveals several methods available for the measurement of $\mathrm{EI}^{3}$. These are "ability-based" methods that measures the mental ability to do with emotions used by Mayer and Salovey, (1997), the "traitbased" method that focuses on socioemotional traits such as "awareness" and the "competency-based" method that measures a set of emotional competencies ${ }^{5}$. 
The Genos Emotional Intelligence Inventory is designed to measure the frequency with which an individual displays emotionally intelligent behaviours across seven dimensions $^{6}$ (Emotional Self-Awareness, Emotional Expression, Emotional Awareness of Others, Emotional Reasoning, Emotional Self-Management, Emotional Management of Others and Emotional SelfControl). The inventory is applicable to adults $(18+)$ in the workplace and the inventory items are scored on a five-point Likert scale, from 'Almost Never' to 'Almost Always'. This inventory provides an overall EI score and seven subscale scores. The Genos EI Concise questionnaire is an internationally recognized tool used to evaluate EI in the corporate and education sectors. This self-administered inventory maybe deemed suitable to assess EI in the Sri Lankan context for several reasons. Firstly, it takes only about 10 minutes to complete which would result in a high response rate and increased accuracy of responses. Furthermore, it has sub scale score reliability levels that meet the minimum standards for research.

Research in the field of Emotional intelligence is sparse in Sri Lanka. Emotional Intelligence has been assessed in the fields of management ${ }^{7}$, military sector and school populations but not in the field of health or medicine in the local context. The few published papers indicated that the Genos Emotional inventory of 71 items had been used, without translation to native language 8 . It is reasonable to assume that tools developed in the west in a non-native language are not appropriate for assessing an attribute such as EI as they will not only cause linguistic problems but also lead to misinterpretation due to cultural discrepancies when administering to a Sri Lankan population'.

Emotional Intelligence is an important attribute especially in the medical sector. The paucity of research on EI of individuals in the healthcare sector could be due to the lack of an appropriate instrument for the assessment of emotional intelligence in Sri
Lanka. Lack of proper data on the emotional intelligence of the corporate or the education sectors were also prime motivators in this endeavour. The importance of using a tool which has been culturally validated and translated to Sinhala is important especially in the case of assessing an attribute such as EI. Such a tool would be useful in obtaining a more comprehensive, unbiased result with regard to EI in Sri Lanka where the English literacy rate is fairly low (14\% of the general population $^{10}$ in spite of an average literacy rate of $91.4 \%)^{11}$

Other tools available to assess EI such as the emotional competence inventory (ECI), BarOn emotional quotient Inventory (EQI), and Mayer-alovey-Caruso Emotional Intelligence Test (MSCETT) ${ }^{12}$, take about 3045 minutes to complete and many consist of over 100 items, which may cause a poor response rate. However the Genos' instrument has sufficient face validity, is easy to understand and require less time to complete.

This instrument when translated would be useful not only as an evaluation tool but also in the recruitment of persons to courses and employment especially in the health sector where a high degree of EI is essential as the care of patients require team work with favourable interpersonal relationships and social skills.

\section{Objective}

To translate the Genos Emotional Intelligence inventory (concise version) to Sinhala language and to validate it to be used among Sri Lankan medical students.

\section{Material and Methods}

The Genos Emotional Intelligence inventory (concise version) consisting of 31 items was accessed with written consent from the authors of the questionnaire. The questionnaire was translated to Sinhalese language (the native language of a majority of Sri Lankans) by an expert in EnglishSinhala translation (Supplementary 
material). The semantics of the questionnaire was considered by the expert during the translation. The Sinhalese questionnaire was translated back into English by another qualified language expert, with a nationally recognized degree in English. Comparisons between the original questionnaire and the back translated version were made. Discrepancies were noted and addressed.

The final version of the Sinhala questionnaire was administered to $3^{\text {rd }}$ year medical undergraduates from the Universities of Peradeniya and Rajarata, Sri Lanka to obtain the face validity. The study sample included 25 students from each faculty, and males and females were included equally within the study sample. The data from the questionnaires was entered into a database, and analyzed using SPSS v.22.0 with regard to reliability of the translation. The internal reliability scores of the seven sub scales were checked by calculating Chronbach's alpha for each sub scale of the EI measurement tool. The values were compared with the reliability scores obtained for the original concise questionnaire $^{6}$. Impact of each of the sub scales on the total reliability was also calculated.

\section{Results}

The response rate was $74 \%(37 / 50)$. The Chronbach's alpha values were obtained for the complete questionnaire and the subscales.

The internal reliability of the complete questionnaire was 0.899. The Chronbach's alpha values for six out of seven sub scales indicated reliability. However, the reliability of EAO sub scale was low. Comparison of the internal reliability scores of the translated questionnaire with the original version, and the respective reliabilities of the complete questionnaire if each item was deleted, is shown in table 1.0.

Table 1.0: Comparison of reliability scores of the translated questionnaire with the reliability scores of the original Genos EI subscales (concise version) and subscale reliability in the whole questionnaire.

\begin{tabular}{|l|l|l|l|}
\hline Subcategories & $\begin{array}{l}\text { Chronbach's } \\
\text { alpha values of } \\
\text { original } \\
\text { questionnaire }\end{array}$ & $\begin{array}{l}\text { Chronbach's } \\
\text { alpha values } \\
\text { of Translated } \\
\text { questionnaire } \\
\text { (internal } \\
\text { reliability) }\end{array}$ & $\begin{array}{l}\text { Chronbach's } \\
\text { alpha values } \\
\text { of Translated } \\
\text { questionnaire } \\
\text { if the sub } \\
\text { category is } \\
\text { deleted }\end{array}$ \\
\hline ESA & 0.75 & 0.801 & 0.90 \\
\hline EE & 0.72 & 0.613 & 0.92 \\
\hline EAO & 0.74 & 0.457 & 0.92 \\
\hline ER & 0.72 & 0.631 & 0.89 \\
\hline ESM & 0.74 & 0.635 & 0.89 \\
\hline EMO & 0.74 & 0.631 & 0.89 \\
\hline ESC & 0.71 & 0.740 & 0.91 \\
\hline Total & 0.93 & 0.899 & \multicolumn{1}{|l}{} \\
\cline { 1 - 2 } & & &
\end{tabular}


The reliability scores of the translated questionnaire were found to be comparable with those of the original questionnaire.

\section{Discussion}

The analysis of the validated and translated questionnaire using Chronbach's alpha revealed the internal validity of the questionnaire to be 0.899 . In general settings it is considered that a Chronbach's alpha value above 0.7 indicates high internal reliability ${ }^{14}$. The overall reliability of the original Genos questionnaire is reported as $0.93^{8}$. Comparison of subscale reliability values with those of the original questionnaire indicates that the internal validity was not disrupted during the process of translation and validation. However it must be noted that the reliability may have been improved further if certain English terms were provided along with the Sinhala version especially of the items in the EAO scale and if cultural confounders, could have been mitigated by a panel of experts subsequent to translation?.

\section{Conclusion}

The validity of the translated version of the Genos Emotional Intelligence inventory (concise version) was established. The Sinhala translation met the minimum reliability scores to be used in the Sri Lankan context. However, items of the EAO sub scale need to be reviewed and revised.

\section{References}

1. Mayer JD, Salovey P. What is emotional intelligence? In: Salovey P, Sluyter D, editors Emotional Development and Emotional Intelligence: Implications for Educators. New York, Basic Books; 1997:3-31

2. Brackett MA, Rivers SE, Salovey P. Emotional Intelligence: Implications for Personal, Social, Academic, and Workplace Success. Social and Personality Psychology Compass 2011; 5:88-103 Doi:10.1111/j.17519004.2010.00334.x
3. Seyal AH, Afzaal T. An investigation of relationship among emotional intelligence, organizational commitment and job satisfaction: evidence from academics in Brunei Darussalam. International Business Research. 2013; 6(3):217.Doi:10.5539/ibr.v6n3p217

4. Weerdt M, Rossi G.The Bar-On Emotional Quotient Inventory (EQ-i): Evaluation of Psychometric Aspects in the Dutch Speaking Part of Belgium.In Rossi G editors Psychology-selected papersINTECH Open Access Publisher; 2012. Doi:10.5772/38875

5. Stys Y, Brown SL. A review of the emotional intelligence literature and implications for corrections. Research branch correctional service of Canada. 2004. http://www.csc-scc.gc.ca/ research/r150-eng.shtml [accessed on 2016.10.12]

6. Gilles E. Gignac. Genos emotional intelligence technical manual 2nd edition, 2010:11-13.

7. Dissanayaka DR, Janadari MP, Chathurani RA. Role of emotional intelligence in organizational learning: An empirical study based on banking sector in Sri Lanka. Proceedings of the International conference on business and information, 2010

8. Jayawardena C, Jayawardena I. Assessing the emotional intelligence of Sri Lankan high school students: A case study. Proceedings of the Management, Knowledge and Learning. International conference, 2012, 449-457

9. Beaton DE, Bombardier C, Guillemin F, Ferraz MB. Guidelines for the process of cross-cultural adaptation of self-report measures. SPINE. 2000; 25(24):3186-91. Doi:10.1097/00007632-20001215000014 
10. Department of census and statistics http://www.statistics.gov.lk/pophousat/ PDF/Population/p9p11\%20Speaking.p df [accessed on 2016.10.12]

11. Literacy rate.(2015) http:// www.statistics.gov.lk/http://www.cbsl. gov.lk/pics n docs $/ 10 \mathrm{pub} /$ docs $/ \mathrm{stati}$ stics/other/Socio_Econ_Data_2015 e. pdf [accessed on 2016.10.12]

12. Chew BH, Zain AM, Hassan F. Emotional intelligence and academic performance infirst and final year medical students: a cross-sectional study. BMC Med Educ.2013 Mar 27;13:44. Doi:10.1186/1472-6920-1344.
13. Benjamin R. Palmer, Stough C, Harmer R, Gignac G. The Genos Emotional Intelligence Inventory: A Measure Designed Specifically for Workplace Applications. Doi:10.1007/978-0-38788370-0_6

14. Peterson, R. A. A meta-analysis of Cronbach's alpha. Journal of Consumer Research, 1994; 21 (2): 381-391. http://www.jstor.org/stable/2489828. 